\title{
Normal pressure hydrocephalus: did publications alter management?
}

\author{
Jan Vanneste, Rob van Acker
}

\begin{abstract}
Forty six Dutch neurologists and neurosurgeons were interviewed to evaluate the clinical value of research articles on normal pressure hydrocephalus (NPH). From this survey it appears that most clinicians still limit investigations to psychometry, CSF-tap test(s), and cisternography. The main reasons for not using other techniques were: their invasiveness, technical complexity, poor availability, lack of time and doubt on their additional predictive value. There is an obvious discrepancy between the quantity of publications on NPH and their impact and their ability to assist clinicians in selecting potential NPH patients for a shunt.
\end{abstract}

Normal pressure hydrocephalus (NPH) combines the clinical triad of dementia, gait disturbance and urinary urgency or incontinence with chronic hydrocephalus and normal CSF pressure measurement at lumbar puncture. ${ }^{12}$ Ventricular shunting leads to a substantial clinical improvement in about $50-70 \%$ of patients when the aetiology is known and in 30$50 \%$ when it is not. ${ }^{34}$ Because the therapeutic successes are obscured by a high frequency of shunt-related complications, ${ }^{56}$ a sizeable literature has appeared describing new tests to select appropriate candidates for shunt procedures. However, most of these techniques are technically complex, invasive or infrequently available; in addition, new tests may only be published when the results are good, leading to a publication bias and overestimation of the clinical value of the test.

As there is increasing pressure to evaluate the practical value of diagnostic procedures and the benefit/harm ratio of therapeutic measures, ${ }^{89} \mathrm{a}$ survey of Dutch neurologists and neurosurgeons was carried out to assess (1) disparities of practice for NPH and (2) opinions concerning the clinical value of recently described ancillary tests on shunting patients with possible NPH.

\section{Method}

All information was obtained by personal telephone interviews. This mode of inquiry was preferred to a postal survey to avoid unreturned questionnaires, to clarify possible uncertainties, and to collect additional information when necessary. Telephone interviews were carried out between September and December 1988. In The Netherlands about 105 neurologists belong to university neurological departments and a further 260 neurologists work in general hospitals of 300 beds or more. Sixty five neurosurgeons are attached to 13 neurosurgical centres. Thirty three neurologists and 13 neurosurgeons were selected for a telephone interview. Selection of respondents was carried out as follows:

1 The chief or one of the staff neurologists of 15 academic and non-academic teaching neurological clinics were telephoned. In centres known for their special interest in diagnosis and treatment of NPH the neurologist most involved in management of NPH was interviewed. In 18 non-teaching general hospitals with 300 beds or more, contact was made with one of the staff neurologists. The number of neurologists in these hospitals ranged from two to four. The hospitals were selected on a geographical basis to obtain a balanced and representative sample throughout The Netherlands.

2 In the same period, 13 neurosurgeons in the 13 Dutch neurosurgical centres were also telephoned. These neurosurgeons were either the heads of their department or had experience with management of NPH patients. In the three neurosurgical centres with established expertise in research on CSF hydrodynamics, the neurosurgeon known to have special interest in the field was interviewed.

We deliberately included all academic and non-academic teaching centres and all centres known for their special interest in NPH, to introduce a selection bias in favour of centres with the greatest manpower, the most advanced technical facilities and the greatest expertise. By doing this we wanted to avoid underestimation of the impact of the literature on the management of NPH. Question 1 was posed to the neurologists, questions $2-5$ to both neurologists and neurosurgeons.

Question 1 How many patients with possible NPH do you see per year, the provisional diagnosis being made on the basis of history, clinical characteristics and CT appearances? Question 2 Do you use the following ancillary examinations to reach a more probable diagnosis of NPH? Enumerated were: neuropsychological asssessment, magnetic resonance imaging (MRI), one or multiple cerebrospinal fluid taps, isotope cisternography, CTcisternography, cerebral blood flow measurements, lumbar infusion test, continuous epi- or sub-dural pressure monitoring, continuous intraventricular pressure monitoring, intraventricular infusion test, other unlisted tests (with further specification). Three 
Table 1 Number of neurologists and neurosurgeons using ancillary tests in patients with possible NPH

\begin{tabular}{|c|c|c|c|c|c|c|c|c|c|c|c|}
\hline Tests & & $\begin{array}{l}\text { Neuro- } \\
\text { psycho- } \\
\text { logical } \\
\text { testing }\end{array}$ & $M R$ & $\begin{array}{l}\text { CSF } \\
\text { tap } \\
\text { test }\end{array}$ & $\begin{array}{l}\text { Isotope } \\
\text { cisterno- } \\
\text { graphy }\end{array}$ & $\begin{array}{l}\text { CT } \\
\text { cisterno- } \\
\text { graphy }\end{array}$ & $\begin{array}{l}\text { Cerebral } \\
\text { blood flow } \\
\text { measurement }\end{array}$ & $\begin{array}{l}\text { Lumbar } \\
\text { infusion } \\
\text { test }\end{array}$ & $\begin{array}{l}\text { EPI-| } \\
\text { subdural ICP } \\
\text { monitoring }\end{array}$ & $\begin{array}{l}\text { Ventricular } \\
\text { pressure } \\
\text { monitoring }\end{array}$ & $\begin{array}{l}\text { Ventricular } \\
\text { infusion } \\
\text { test }\end{array}$ \\
\hline $\begin{array}{l}\text { Neurologists } \\
(\mathbf{n}=33) \\
1 \star \star\end{array}$ & $\begin{array}{l}\text { Yes } \\
\text { No } \\
\text { Sometimes }\end{array}$ & $\begin{array}{r}24 \\
8 \\
1\end{array}$ & $\begin{array}{r}2 \\
30 \\
1\end{array}$ & $\begin{array}{r}22 \\
6 \\
5\end{array}$ & $\begin{array}{r}17 \\
13 \\
3\end{array}$ & $\begin{array}{r}5 \\
24 \\
4\end{array}$ & $\begin{array}{r}2 \\
31 \\
0\end{array}$ & $\begin{array}{c}2^{\star} \\
27 \\
4\end{array}$ & $\begin{array}{c}5^{\star \star} \\
25 \\
3\end{array}$ & $\begin{array}{c}2^{\star \star} \\
2\end{array}$ & $\begin{array}{l}0 \\
32 \\
1 \star \star\end{array}$ \\
\hline $\begin{array}{l}\text { Neurosurgeons } \\
(\mathrm{n}=13)\end{array}$ & $\begin{array}{l}\text { Yes } \\
\text { No } \\
\text { Sometimes }\end{array}$ & $\begin{array}{l}6 \\
6 \\
1\end{array}$ & $\begin{array}{r}1 \\
11 \\
1\end{array}$ & $\begin{array}{r}12 \\
0 \\
1\end{array}$ & $\begin{array}{l}6 \\
5 \\
2\end{array}$ & $\begin{array}{r}2 \\
10 \\
1\end{array}$ & $1^{11^{\star}}$ & $\begin{array}{c}2^{\star} \\
11 \\
0\end{array}$ & $\begin{array}{l}4 \\
8 \\
1\end{array}$ & $\begin{array}{l}4 \\
9 \\
0\end{array}$ & $\begin{array}{r}2 \\
11 \\
0\end{array}$ \\
\hline
\end{tabular}

${ }^{\star}$ Tests performed either by the neurologist or the neurosurgeon. ${ }^{\star \star}$ Tests considered by the neurologist but performed by the neurosurgeon.

answers on each enumerated test were possible: yes/sometimes/never. The response was categorised as "yes" when the test was performed either routinely or on indication in cases when the diagnosis remained in doubt.

Question 3 If you use cisternography, do you use the following cisternographic patterns to diagnose NPH? (a) ventricular stasis with contrast for 24 hours; (b) ventricular stasis persisting for 48 hours or longer; (c) absence or minimal presence of contrast at the convexity after 48 hours. The following answers were possible: yes/possible or uncertain/no; responses were not mutually exclusive. The responses "possible or uncertain" were arbitrarily categorised as "no" because we considered that in these cases, no firm conclusions were drawn from the test.

Question 4 Can you cite a test which you consider to provide substantial additional information for the decision for a patient to be given a shunt? Possible answers: yes (specify what test)/no.

Question 5 Only to the respondents not considering continuous intracranial pressure monitoring or CSF-infusion tests: would you consider these tests, provided that sufficient time and technical facilities were available? Possible answers 1) yes, 2) no, 3) don't know.

\section{Results}

All the neurologists agreed to a telephone assessment. Eleven neurosurgeons responded to the questions and two did not, commenting that their opinions and policy were identical to those of the neurologists of the same hospital. For these two neurosurgeons, we used the corresponding neurologist's responses. To avoid duplication as much as possible, the tests performed or ordered by the neurologists and those performed by the neurosurgeons were listed separately.
Question 1 (incidence of NPH): almost all neurologists stated that they examined between 700 and 1000 new patients in one year and that in the same period they encountered only one or two potential NPH patients.

Question 2 (table 1): It is obvious that most neurologists restricted ancillary testing to neuropsychological assessment (24/33), CSF tap test (22/33) and isotope cisternography $(17 / 33)$ and that in only $30 \%$ of the neurosurgical centres prolonged intracranial pressure monitoring is currently used in patients with possible NPH.

Question 3 (table 2): The variability of opinions on the value of cisternography clearly emerged from this question: $36 \%$ of respondents considered the test as a useless procedure; from the remaining $64 \%$ using cisternography, $41 \%$ considered that ventricular stasis for 24 hours was sufficient to suggest $\mathrm{NPH}$; only $24 \%$ considered a cisternal block as important and only $17 \%$ adhered to the strict criteria of prolonged ventricular stasis of 48 hours or more plus a cisternal block.

Question 4 Table 3 illustrates that neurologists preferred the CSF-tap test and cisternography and that among neurosurgeons only CSF removal had value in predicting the outcome after surgery.

Question 5 Table 4 shows that the need for intracranial pressure monitoring and CSF infusion tests was obviously low, even when time and technical restrictions would not play a role.

It is evident that biases are inevitable in this mode of data collection; we tried to limit them by offering as many unambiguous questions as possible. No firm conclusions were drawn from numerical data concerning the incidence of $\mathrm{NPH}$, as these data were only estimations. We believed neurologists who said that their responses concerning the ancillary tests (question 2 , table 1) reflected the management of NPH

Table 2 Cisternographic criteria for NPH

\begin{tabular}{|c|c|c|c|c|c|c|}
\hline Categories of responses & No value & $\begin{array}{l}\text { Stasis } \\
24 \text { hours }\end{array}$ & $\begin{array}{l}\text { Stasis } \\
48 \text { hours }\end{array}$ & $\begin{array}{l}\text { Stasis } \\
24 \text { hours }+ \\
\text { cisternal } \\
\text { block }\end{array}$ & $\begin{array}{l}\text { Stasis } \\
48 \text { hours }+ \\
\text { cisternal } \\
\text { block }\end{array}$ & $\begin{array}{l}\text { No opinion } \\
\text { or other } \\
\text { criteria }\end{array}$ \\
\hline Number of neurologists & 9 & 10 & 5 & 2 & 4 & 3 \\
\hline $\begin{array}{l}\text { Number of neurosurgeons } \\
(n=13)\end{array}$ & 6 & 1 & 3 & 0 & 2 & 1 \\
\hline
\end{tabular}


Table 3 Preferred test to provide additional diagnostic information

\begin{tabular}{llllllll}
\hline Tests & No test & $\begin{array}{l}\text { CSF } \\
\text { removal }\end{array}$ & $\begin{array}{l}\text { Cisterno- } \\
\text { graphy }\end{array}$ & $\begin{array}{l}\text { Lumbar } \\
\text { infusion } \\
\text { test }\end{array}$ & $\begin{array}{l}\text { Epi-/subdural } \\
\text { ICP } \\
\text { monitoring }\end{array}$ & $\begin{array}{l}\text { Ventricular } \\
\text { pressure } \\
\text { monitoring }\end{array}$ & Others $\star \star$ \\
\hline Neurologists $(\mathrm{n}=33)$ & 9 & 7 & 8 & 3 & 1 & 2 & 3 \\
Neurosurgeons $(\mathrm{n}=13)$ & 1 & 6 & 1 & 2 & 1 & 1 & 1 \\
\hline
\end{tabular}

$\star \star$ Others: doppler measurements before and after CSF removal: 2; temporary lumbar external CSF drainage: 1; neuropsychological assessment; 1 .

patients in their department. Conversely, we considered that responses to questions 3-5 were personal and did not necessarily reflect the opinions of other colleagues in the same department.

\section{Discussion}

In highly probable NPH patients with a short history, a typical clinical triad, demonstrable cause of hydrocephalus and persuasive CT findings, the decision to shunt a patient was not a problem. In less typical cases, almost all respondents felt the need to perform ancillary tests. As the predictive value of a test depends on the prevalence of a disease $\mathrm{e}^{10}$ we first tried to estimate the incidence and prevalence of NPH. Estimates of the respondents mirrored the low incidence of NPH in the literature: no more than 5-10 patients/year are given shunts for idiopathic NPH in most major neurosurgical centres $^{411}$ and NPH as a cause of dementia is rare, ranging from $0-5 \% .^{12}$ This low prevalence necessitates rigorous preselection before performing ancillary tests, as false positive results of a test are inversely proportional to the pretest probability of a disease. ${ }^{10}$

In accordance with review articles, ${ }^{314}$ most respondents stressed that this preselection should be based on strict adherence to the clinical criteria. The literature on ancillary tests and its impact on management are now reviewed.

\section{Neuropsychological assessment}

In doubtful cases, assessment of the neuropsychological functions may contribute to the diagnosis of NPH: the profile of hydrocephalic dementia ${ }^{15}$ has similarities with other so-called "subcortical dementias"16 including slowing of mental processing, difficulty in planning complex actions and mental shifting, impaired recall on memory tests and absence of cortical dysfunction. These patterns of cognitive impairment are different from "cortical" dementias such as Alzheimer's disease and may assist the clinician in differential diagnosis. ${ }^{1617}$ In addition, serial psychometric testing in chronic hydrocephalus may quantify even subtle pre-

Table 4 Would you consider continuous ICP monitoring or lumboventricular infusion when available?

\begin{tabular}{llrl}
\hline & Yes & No & Don't know \\
\hline Neurologists $\left(\mathrm{n}=30^{\star}\right)$ & 4 & 22 & 4 \\
Neurosurgeons $\left(\mathrm{n}=7^{\star}\right)$ & 2 & 4 & 1 \\
\hline
\end{tabular}

*Only to respondents not already using these tests. operative deterioration or post-operative shunt dysfunction or improvement. ${ }^{18-20}$ We were somewhat surprised that $70 \%$ of the neurologists thought that a thorough neuropsychological assessment should be made, in spite of a limited number of articles underscoring the importance of assessment of cognitive impairment and the value of serial psychometry in NPH.

\section{Magnetic resonance imaging (MRI)}

Recent publications outlined some MRI features that suggested $\mathrm{NPH}$, including a marked CSF voiding sign (CVS) in the aqueduct, corpus callosum thinning, high periventricular signals and absence or less extensive areas of increased white matter signal. ${ }^{21}$ However, the CVS sign is not specific for $\mathrm{NPH}$ and white matter involvement does not preclude a favourable shunt response. ${ }^{22}$ Uncertainty remains about the additional costs of MRI for detecting a few additional treatable patients with NPH. The use of MRI by our respondents was negligible, probably mainly due to its limited availability and high costs. Even in centres with MRI this facility was infrequently performed, because of its doubtful additional predictive value.

\section{CSF tap test (s)}

Both improvement or lack of improvement after CSF removal or after continuous lumbar CSF drainage have been described as good predictive tests to select shunt candidates. ${ }^{23} 24$ Wikkelsö reported that the CSF tap test was able to predict the degree of improvement. ${ }^{25}$ However, validation of these results by other prospective studies is still lacking and a negative CSF tap test does not exclude improvement after CSF diversion. ${ }^{26}{ }^{27}$ In spite of uncertainty on the value of a negative CSF tap test, it ranked at the top of the preferred tests and many respondents elected not to shunt a patient when the test was negative.

\section{Cisternography}

Since the first description in diagnosing communicating $\mathrm{NPH}^{28}$ the predictive value of cisternography with isotopes has remained a matter of controversy. ${ }^{34142930}$ Some authors found that cisternography remained a useful test when strict adherence to the criteria of a "positive" cisternography (see results, question 3) had been maintained and used in conjunction with other diagnostic techniques.

The controversy in the literature was mirrored in our survey. It was striking that only $17 \%$ of the neurologists adhered to strict criteria and that nearly $50 \%$ of the neuro- 
surgeons considered the test as useless. The impact of reports showing a close correlation between isotope cisternography and CT cisternography ${ }^{31} 32$ was also negligible. Additional comments on cisternography revealed that results were frequently liberally interpreted and, in fact, had limited influence on surgical decisions. In some cases an additional role appeared to diminish the uncomfortable feeling of hesitancy by doing a test before taking a therapeutic decision.

\section{Cerebral blood flow (CBF) measurements}

Many articles on NPH described CBF measurements before and after CSF removal or after shunting, using imaging with xenon ${ }^{133}$, SPECT or PET scan. ${ }^{33-37}$ Clinical improvement when decreased cerebral blood flow increased after CSF removal or after a shunt has been described, ${ }^{33}$ 35-37 although this has not been confirmed by others. ${ }^{34}$ No respondent used xenon ${ }^{133}$ or SPECT and only two neurologists evaluated the CBF after CSF removal by measuring changes in carotid flow velocity before and after CSF removal (the "Doppler-lp test"). ${ }^{38}$

\section{Continuous intracranial pressure monitoring ( ICPm) and CSF infusion tests}

Further evaluation of CSF hydrodynamics by means of ICPm or CSF infusion tests in doubtful cases had few adherents. Although ICPm has been reported as one of the best tests to predict improvement after a shunt, ${ }^{39-42}$ only five of the 13 neurosurgical centres use this procedure; four others abandoned it because of technical problems, the patient's lack of cooperation or because of doubts on the additional predictive value. For the same reasons the lumbar CSF infusion test ${ }^{43}{ }^{44}$ was used in only two centres.

No neurosurgeon assessed the conductance to $\mathrm{CSF}$ outflow $\left(\mathrm{C}_{\text {out }}\right)^{1145}$ in spite of a predictive value of $96 \%$ (confidence intervals $66 \%$ $100 \%$ ). Invasiveness, technical complexity and lack of time were the main reasons for reticence. However, even when technical aspects and lack of time would not limit their use, only a small minority of both neurologists and neurosurgeons would consider the test, because of uncertainty concerning its general rule. The latter assumption has recently been suggested by Vorstrup et al, who found a predictive value of $\mathrm{C}_{\text {out }}$ of only $58 \%$ (confidence intervals $29 \%-82 \%)^{37}$

In conclusion it appeared from our survey that although one of the functions of medical literature is to assist clinicians in making optimal decisions about their patients, recent articles on NPH describing new techniques had a negligible influence on management. Psychometry, CSF removal, and isotope cisternography were the only tests used by more than $50 \%$ of the respondents, in spite of their limited diagnostic and predictive value. Reluctance to use new tests in NPH was mainly due to the combination of unfamiliarity with the procedures and the complexity, invasiveness or unavailability of many of them. In addition, many articles on NPH contain substantial methodological flaws including the lack of appropriate statistical analysis or the absence of a control group. Results of prospective randomised controlled trials-repeatedly advocated in review articles-are still lacking.

Symon established in 1977 that 12 years after studies on NPH clinicians remained puzzled. Another 12 years after the first studies, this statement still holds true. Proliferation of research and clinical articles further increased the complexity of the puzzle, without clarifying the problem on how patients with uncertain NPH should be managed. Clinicians are still awaiting tests and guidelines with more practical value. In the mean time, "the proof of the shunt"-a still common albeit unsatisfying strategy-will remain in vogue in many centres.

We are most grateful to all our colleagues who kindly responded to the telephone interviews. We are also indebted to Professor $\mathrm{H}$ van Crevel and Drs G Davies and M Laman for their useful van Crevel

1 Hakim S, Adams RD. The special clinical problem of symptomatic hydrocephalus with normal cerebrospinal fluid pressure. Observations on cerebrospinal fluid hydrodynamics. J Neurol Sci 1965;2:307-27.

2 Adams RD, Fischer CM, Hakim S, Ojemann RG, Sweet WH. Symptomatic occult hydrocephalus with "normal" cerebrospinal fluid pressure. A treatable syndrome. N Eng JMed 1965;273:117-26.

3 Pickard JD. Normal pressure hydrocephalus-to shunt or not to shunt. In: Warlow C, Garfield J, eds. Dilemmas in the management of the neurological patient. Edinburgh: the management of the neurological pat

4 Black P McL, Ojemann RG, Tzouras A. CSF shunts for dementia, incontinence, and gait disturbance. Clin Neurosurg 1985;32:632-51

5 Udvarhelyi GB, Wood JH, James AE Jr, et al. Results and complications in 55 shunted patients with normal pressure hydrocephalus. Surg Neurol 1975;3:271-5.

6 Greenberg JO, Shenkin HA, Adam R. Idiopathic norma pressure hydrocephalus-a report of 73 patients. J Neurol Neurosurg Psychiatry 1977;40:336-41.

7 Sheps SB, Schechter MT. The assessment of diagnostic tests. J Am Med Assoc 1984;252:2418-22.

8 Sackett DL, Haynes RB, Tugwell P. The selection of diagnostic tests. Clinical epidemiology. Boston: Little, Brown, 1985:47-57.

9 Koprowski CD, Longstreth WT Jr, Cebul RD. Clinical Neuroepidemiology: III Decisions. Arch Neurol 1989;46:223-33.

10 Vecchio TJ. Predictive value of a single diagnostic test in unselected populations. N Engl J Med 1966;274:1171-3.

11 Børgesen SE, Gjerris F. The predictive value of conductance to outflow of cerebrospinal fluid in normal pressure hydrocephalus. Brain 1982;105:65-86.

12 Larson EB, Reifler BV, Featherstone HJ, English DR. Dementia in elderly outpatients: a prospective study. $A n n$ Intern Med 1984;100:417-24.

13 Clarfield AM. The reversible dementias: do they reverse? Ann Intern Med 1988;109:476-86.

14 Katzman R. Normal pressure hydrocephalus. In: Katzman R, Terry RD, Bick KL. Alzheimer's disease: senile dementia and related disorders. Aging 1978;7:115-24.

15 Benson DF. Hydrocephalic dementia. In: Frederiks JAM, Vinken PJ, Bruyn GW, Klawans HL, eds. Handbook of Vinken PJ, Bruyn GW, Klawans HL, eds. Handbook of
Clinical Neurology, Amsterdam: Elsevier, 1985;46: Clinical

16 Cummings JL, Benson DF. Subcortical dementia: review of an emerging concept. Arch Neurol 1984;41:874-9.

17 Gustafson L, Hagberg B. Recovery in hydrocephalic dementia after shunt operation. J Neurol Neurosurg Psychiatry 1978;41:940-7.

18 Thomsen AM, Børgesen SE, Bruhn P, Gjerris P. Prognosis of dementia in normal-pressure hydrocephalus after a shunt operation. Ann Neurol 1986;20:304-10.

19 Whittle IR, Johnston IH, Besser M. Intracranial pressure changes in arrested hydrocephalus. J Neurosurg 1985 82:77-82.

20 Torkelson RD, Leibrock LG, Gustavson JL, Sundell RR Neurological and neuropsychological effects of cerebrospinal fluid shunting in children with assumed arrested ("normal pressure") hydrocephalus. J Neurol Neurosur Psychiatry 1985;48:799-806.

21 Bradley WG Jr, Kortman KE, Burgoyne B. Flowing cerebrospinal fluid in normal and hydrocephalic states: appearance on MR images. Radiology 1986;159:611-6.

22 Jack CR, Mokri B, Laws ER, Houser OW, Baker HL, Petersen RC. MR findings in normal-pressure hydrocephalus: significance and comparison with other forms of dementia. J Comput Assist Tomogr 1987;11:923-31. 
23 Wikkelsö C, Andersson H, Blomstrand C. The clinical effect of lumbar puncture in normal pressure hydrocephalus. $J$ of lumbar puncture in normal pressure hydro

24 Haan J, Thomeer RTWM. Predictive value of temporary external lumbar drainage in normal pressure hydroexternal lumbar drainage in normal

25 Wikkelsö C, Andersson H, Blomstrand C, Lindqvist G, Svendsen $P$. Normal pressure hydrocephalus. Predictive value of the cerebrospinal fluid tap-test. Acta Neurol Scand 1986;73:566-73.

26 Fishman RA. Normal-pressure hydrocephalus and arthritis. N Engl J Med 1985;312:1255-6.

27 Vanneste J, Hyman R. Non-tumoural aqueduct stenosis and normal pressure hydrocephalus in the elderly. $J$ Neurol Neurosurg Psychiatry 1986;49:529-35.

28 Bannister R, Gilford E, Kocen R. Isotope encephalography in the diagnosis of dementia due to communicating hydrocephalus. Lancet 1967;ii:1014-7.

29 Guidetti B, Gagliardi FM. Normal pressure hydrocephalus. In: Amaducci $L$ et al, eds. Aging of the brain and dementia. In: Amaducci L, et al, eds. Aging of the brain

30 Benson DF. Neuroimaging and dementia. In: Hutton JTh ed. Dementia, Neurologic Clinics Philadelphia: WB Saunders Co, 1986;4:341-53.

31 Inaba $Y$, Hiratsuka $H$, T suyumu $M$, Suganuma $Y$, Okada $K$, Fujiwara K, Takasato Y. Diagnostic value of CT cisternography with intrathecal metrizamide enhancement comparison with isotope cisternography. Neuroradiology 1978;16:214-5.

32 Enzmann DR, Norman D, Price DC, Newton TH Metrizamide and radionuclide cisternography in communicating hydrocephalus. Neuroradiology 1979;130: 681-6.

33 Mathew NT, Meyer JS, Hartmann A. Abnormal cerebrospinal fluid blood flow dynamics. Implications in diagspinal fluid blood fow dynamics. in normal pressure nosis, treatment and prognosis in normal

34 Kushner M, Younkin D, Weinberger J, Hurtig H, Goldberg $\mathrm{H}$, Reivich $M$. Cerebral hemodynamics in the diagnosis of normal pressure hydrocephalus. Neurology 1984;34: 96-9.
35 Jagust WJ, Friedland RP, Budinger TF. Positron emission tomography with $\left({ }^{18} \mathrm{~F}\right)$ Fluorodeoxyglucose differentiates normal pressure hydrocephalus from Alzheimer-type dementia. J Neurol Neurosurg Psychiatry 1985;48:1091-6. 36 Graff-Radford NR, Rezai K, Godersky JC, Eslinger P, Graff-Radford NR, Rezai K, Godersky JC, Eslinger P,
Damasio H, Kirchner PT. Regional cerebral blood flow in Damasio H, Kirchner PT. Regional cerebral blood flow in
normal pressure hydrocephalus. $J$ Neurol Neurosurg Psynormal pressure hydrocepha
chiatry 1987;50:1589-96.

37 Vorstrup S, Christensen J, Gjerris F, Sørensen PS, Thomsen $A M$, Paulson OB. Cerebral blood flow in patients with normal-pressure hydrocephalus before and shunting. Neurosurg 1987;66:379-87.

38 Schoonderwaldt HC, Colon E, Hommes OR, Schijns WA Changes in carotid flow velocity induced by lowering cerebrospinal fluid pressure in normal pressure hydrocephalus. J Neurol 1978;218:17-22.

39 Symon L, Dorsch NWC. Use of long-term intracrania pressure measurement to assess hydrocephalic patients prior to shunt surgery. $J$ Neurosurg 1975;42:258-73.

40 Symon $L$, Hinzpeter $T$. The enigma of normal pressure hydrocephalus: Tests to select patients for surgery and to hydrocephalus: Tests to select patients for surgery and to

41 Crockard HA, Hanlon K, Duda EE, Mullan JF. Hydrocephalus as a cause of dementia: Evaluation of computerised tomography and intracranial pressure monitoring. $J$ Neurol Neurosurg Psychistry 1977;40:736-40.

42 Pickard JD, Teasdale G, Matheson M, Lindsay $\mathrm{K}$, Galbraith S, Wyper D, MacPherson P. Intraventricular pressure waves-the best predictive test for shunting in normal pressure hydrocephalus. In: Shulman K, Marmarou A, Miller JD, et al eds. Intracranial Pressure IV. Berlin: Springer-Verlag, 1980:498-500.

43 Katzman R, Hussey F. A simple constant infusion manometric test for measurement of CSF absorption. 1. Rationale and method. Neurology 1970;20:534-44.

44 Tans JTJ. Differentiation of normal pressure hydrocephalus and cerebral atrophy by computed tomography and spinal and cerebral atrophy by computed tomog

45 Børgesen SE, Gjerris F. Relationships between intracranial pressure, ventricular size, and resistance to CSF outflow. pressure, ventricular size, and
$J$ Neurosurg 1987;67:535-9. 